\title{
Literature Review of Emotional Intelligence and Mental Health
}

\author{
Mary Rachelle Reyes-Wapano, $\mathrm{PhD}$ \\ Xavier Ateneo, Cagayan De Oro City, Philippines
}

\begin{abstract}
The aim of this review paper is twofold: This paper reviews the concept of emotional intelligence and related terms such as emotion, intelligence, and emotional intelligence. A distinction will also be made between the different models of emotional intelligence, the one that emphasizes mental ability from those that combine mental abilities with personality traits. This paper maintains that the Mayer and Salovey definition of emotional intelligence lends itself to be model that can explain the adolescent emotional intelligence: that emotional intelligence as an ability to understand and regulate one's emotions is an ability that can be learned and improved; that with age, an individual's level of emotional competency progresses.

The second aim of this review is to show and examine the existing literature on the relationship of emotional intelligence and mental health. Specifically, this paper reviews the literature on the relationship between emotional intelligence and anxiety; relationship between emotional intelligence and depression; relationship between emotional intelligence and resilience; and relationship between emotional intelligence and self-efficacy. This paper contends that emotional intelligence is negatively predicts anxiety and depression; and positively predicts selfefficacy and resilience.
\end{abstract}

\section{EMOTION INTELLIGENCE AND RELATED TERMS}

$\mathrm{M}$ ayer and Salovey (2004) describe emotion as one of three or four sets of mental operations. Motivation, identified as the first set of mental processes, is activated as a response to physical drive such as hunger, thirst or sexual needs, which directs organism to satisfy its survival needs. They further proposed that emotions seemed to evolve among mammalian species to point to actual or perceived changes in the environment and to elicit responses to a changing environment, whereas cognition allows the organism to solve problems and learn from its environment and includes learning, memory, and problem solving, information processing that is conscious and flexible (Mayer \& Salovey, 2004). The term emotional intelligence suggests the converging of emotion and cognition.

Sternberg (1997) defines intelligence as a "necessity of mental ability for adaptation in, or shaping or selection of any environmental context, not just in any one particular environmental context" (p. 1033). This is similar to the definition proposed by Weschler in 1958 as the individual's "global capacity to act purposely, to think rationally, and to deal effectively with his environment" (as cited in Mayer \& Ciarrochi, 2006, p. 262). The term "intelligence" generally implies information gathering, processing the information gathered, and reasoning using information. In 1921, Terman (as cited in Sternberg, 2000) described an intelligent individual as one who can perform abstract thinking. Traditionally, abstract thinking has been considered as a significant indicator of intelligence. Typically, intelligence is regarded as intellectual capacity for problem-solving, analysis, and abstract reasoning.

\section{Emotional Intelligence}

Drawing from this cooperative combination of intelligence and emotion, emotional intelligence may be defined as a generic ability in perceiving emotions in oneself and in others, in managing emotions, and in coping effectively in emotionalladen situations (Zeidner, Matthews, \& Roberts, 2009).

The concept of emotional intelligence can be traced to John Dewey's conception of social intelligence in 1909: The "ultimate moral motives and forces are nothing more or less than social intelligence - the power of observing and comprehending social situations - and social power-trained capacities of control-at work in the service of social interests and aims" (Landy, 2006, p.84). Similarly, Thorndike in 1920 described social intelligence as "the ability to manage and understand men and women, boys and girls, to act wisely in human relations" (as cited in Zeidner et al., 2009, p. 6). Thorndike's 1937 social intelligence refers to one's ability to understand and deal with other people and to engage in meaningful, adaptive interaction with them (Thorndike, 1920, as cited in Zeidner et al., 2009). This is thought to be the individual's ability to process and utilize emotional information related to key areas of effective functioning in everyday life (Mayer \& Salovey, 1997). It is a combination of factors that is found to be related to motivation (Christie, Jordan, Troth, Lawrence, 2007); impulse control (Tice, Bratslavsky, \& Baumeister, 2001); mood regulation (Gohm) 2003 and the ability to persist in the face of frustration (Yoo \& Salovey, 2008). Evidence reveals that emotional intelligence is a predictor of academic (Downey, Mountstephen, Lloyd, Hansen, \& Stough, 2008) and professional (Abraham, 2005) success.

\section{MODELS OF EMOTIONAL INTELLIGENCE}

This paper attempts to make distinction among different models of emotional intelligence, the one that emphasizes mental ability from those that combine mental abilities with personality traits. 
Currently, there are three major models of emotional intelligence. The model proposed by Salovey and Mayer (1997) conceives of EI as an ability to reason with emotions and to utilize emotions to enhance thoughts. The second model proposed by Bar-On (1997) perceives EI as a mix of cognitive intelligence and aspects of personality and emphasis is placed on how the combination of cognitive ability and personality characteristics contribute to one's wellbeing. The model proposed by Goleman (1998) also conceptualizes EI as a mixed ability, that is, involving cognitive skills and personality aspects with emphasis on workplace success.

\section{Mayer and Salovey four branch model}

The Mayer and Salovey EI model (Salovey \& Mayer, 1990) integrates key concepts from the theories of intelligence and emotion. The notion that intelligence involves the capacity to carry out abstract reasoning comes from intelligence theory while the notions that emotions are indicators that communicate general and understandable meaning about relationships and that certain emotions are basic as they are universal come from emotion research (Mayer, Salovey, \& Caruso, 2002 ). The Mayer and Salovey model proposed that there are individual differences in how people process emotion-laden information and how they relate emotional processing to general cognition.

They further conceive of this emotional ability to manifest itself in certain adaptive behaviors.

Based on the model of intelligence, the Mayer and Salovey EI model attempts to define emotional intelligence within the context of the standard criteria for intelligence (Mayer, Salovey, Caruso, \& Sitarenios, 2003). This model proposes that emotional intelligence is composed of two areas: (a) experiential ability, which is the ability to perceive, respond and, (b) regulate emotion without the necessity of understanding; and strategic ability, which relates to the ability to understand and manage emotions without the necessity of adequate perception of feelings. In turn, each area is segregated into two branches, hence, the term "four branch model." The four branch model of EI then refers to the four areas of competencies that collectively illustrate the divisions of emotional intelligence. This model describes EI as divided into four areas: (a) emotional perception, (b) emotional assimilation, (c) emotional understanding, and (d) emotional management (Mayer, Salovey \& Caruso, 2004). This model is illustrated in Figure 1.

The first Branch, emotional perception, the initial and basic area, and involves the capacity to identify emotion in others' facial and postural expressions. This includes the nonverbal perception and reception of emotions expressed via the face, voice, and other related communication (Ekman \& Friesen, 1975, as cited in Mayer et al., 2004).The accurate perception of emotion is the basis of the processing of emotional information. This first area of EI then, which relates to the capacity to correctly perceive emotions through nonverbal channels, provides an essential basis for more advanced understanding of emotions. The abilities involved in this first branch include: the ability to identify emotion in one's bodily states, feelings and thought; the ability to express emotions accurately, and to express needs related to those feelings; and the ability to distinguish between accurate and inaccurate, honest or dishonest feeling expressions.

The second Branch, emotional assimilation, involves the capacity of emotions to guide the cognitive system and promote thinking. After emotion is perceived, emotion may facilitate thinking at the basic levels of processing. This branch, also referred to as "emotional integration" focuses on the contribution of emotion to logic and reasoning (Mayer, Salovey \& Caruso, 2000). This model demonstrates how emotions facilitate cognition in several ways: First, emotions may present cues and prioritizations of problems directing thinking toward matters that are considered as most critical. Emotions act as an interrupt or cue when it allows the individual to respond to the most pressing needs in real.

\begin{tabular}{|c|c|c|c|}
\hline \multicolumn{4}{|c|}{ Branch1: Perception, Appraisal and Expression of Emotion } \\
\hline $\begin{array}{l}\text { Ability to } \\
\text { identify } \\
\text { emotion in } \\
\text { one's physical } \\
\text { states, } \\
\text { feelings, and } \\
\text { thoughts. }\end{array}$ & $\begin{array}{l}\text { Ability to identify } \\
\text { emotions in other } \\
\text { people, designs, } \\
\text { artwork, etc. } \\
\text { through language, } \\
\text { sound, } \\
\text { appearance, and } \\
\text { behaviour. }\end{array}$ & $\begin{array}{c}\text { Ability to } \\
\text { express } \\
\text { emotions } \\
\text { accurately and } \\
\text { to express } \\
\text { needs related to } \\
\text { those feelings. }\end{array}$ & $\begin{array}{l}\text { Ability to } \\
\text { discriminate } \\
\text { between } \\
\text { accurate and } \\
\text { inaccurate, } \\
\text { honest versus } \\
\text { dishonest } \\
\text { expressions of } \\
\text { feeling. } \\
\end{array}$ \\
\hline \multicolumn{4}{|c|}{ Branch 2: Emotional Facilitation of Thinking } \\
\hline $\begin{array}{l}\text { Emotions } \\
\text { prioritize } \\
\text { thinking by } \\
\text { directing } \\
\text { attention to } \\
\text { important } \\
\text { information. }\end{array}$ & $\begin{array}{l}\text { Emotions are } \\
\text { sufficiently vivid } \\
\text { and available that } \\
\text { they can be } \\
\text { generated as aids } \\
\text { to judgment and } \\
\text { memory } \\
\text { concerning } \\
\text { feelings. }\end{array}$ & $\begin{array}{l}\text { Emotional } \\
\text { mood swings } \\
\text { change the } \\
\text { individual's } \\
\text { perspective } \\
\text { from optimistic } \\
\text { to pessimistic, } \\
\text { encouraging } \\
\text { consideration } \\
\text { of multiple } \\
\text { points of view. }\end{array}$ & $\begin{array}{l}\text { Emotional } \\
\text { states } \\
\text { differentially } \\
\text { encourage } \\
\text { specific } \\
\text { problem- } \\
\text { solving } \\
\text { approaches } \\
\text { such as when } \\
\text { happiness } \\
\text { facilitates } \\
\text { inductive } \\
\text { reasoning and } \\
\text { creativity. } \\
\end{array}$ \\
\hline \multicolumn{4}{|c|}{$\begin{array}{c}\text { Branch 3: Understanding and Analyzing Emotions; Employing } \\
\text { Emotional Knowledge }\end{array}$} \\
\hline $\begin{array}{l}\text { Ability to } \\
\text { label } \\
\text { emotions and } \\
\text { recognize } \\
\text { relations } \\
\text { among the } \\
\text { words and the } \\
\text { emotions } \\
\text { themselves, } \\
\text { such as the } \\
\text { relation } \\
\text { between } \\
\text { liking and } \\
\text { loving }\end{array}$ & $\begin{array}{l}\text { Ability to } \\
\text { interpret the } \\
\text { meanings that } \\
\text { emotions convey } \\
\text { regarding } \\
\text { relationships, } \\
\text { such as that } \\
\text { sadness often } \\
\text { accompanies a } \\
\text { loss. }\end{array}$ & $\begin{array}{c}\text { Ability to } \\
\text { understand } \\
\text { complex } \\
\text { feelings: } \\
\text { simultaneous } \\
\text { feelings of love } \\
\text { and hate or } \\
\text { blends such as } \\
\text { awe as a } \\
\text { combination of } \\
\text { fear and } \\
\text { surprise. }\end{array}$ & $\begin{array}{l}\text { Ability to } \\
\text { recognize } \\
\text { likely } \\
\text { transitions } \\
\text { among } \\
\text { emotions, such } \\
\text { as the } \\
\text { transition from } \\
\text { anger to } \\
\text { satisfaction or } \\
\text { from anger to } \\
\text { shame }\end{array}$ \\
\hline
\end{tabular}




\begin{tabular}{|c|c|c|c|}
\hline \multicolumn{4}{|c|}{$\begin{array}{l}\text { Branch 4: Reflective Regulation of Emotion to Promote Emotional and } \\
\text { Intellectual Growth }\end{array}$} \\
\hline $\begin{array}{l}\text { Ability to stay } \\
\text { open to } \\
\text { feelings, both } \\
\text { those that are } \\
\text { pleasant and } \\
\text { those that are } \\
\text { unpleasant. }\end{array}$ & $\begin{array}{c}\text { Ability to } \\
\text { reflectively } \\
\text { engage or detach } \\
\text { from an emotion } \\
\text { depending upon } \\
\text { its judged } \\
\text { informativeness } \\
\text { or utility. }\end{array}$ & $\begin{array}{l}\text { Ability to } \\
\text { reflectively } \\
\text { monitor } \\
\text { emotions in } \\
\text { relation to } \\
\text { oneself and } \\
\text { others, such as } \\
\text { recognizing } \\
\text { how clear, } \\
\text { typical, } \\
\text { influential or } \\
\text { reasonable they } \\
\text { are. }\end{array}$ & $\begin{array}{l}\text { Ability to } \\
\text { manage } \\
\text { emotion in } \\
\text { oneself and } \\
\text { others by } \\
\text { moderating } \\
\text { negative } \\
\text { emotions and } \\
\text { enhancing } \\
\text { pleasant ones, } \\
\text { without } \\
\text { repressing or } \\
\text { exaggerating } \\
\text { information } \\
\text { they may } \\
\text { convey. }\end{array}$ \\
\hline
\end{tabular}

Time (Maes, 1996). Emotions, too, can allow the perceiver to prioritize cues such that the most effective cues are entered into the problem-directed thinking (Matthews, 1997).

Secondly, emotions also aid cognition by functioning as a second memory store about the emotion itself. Thirdly, emotions aid intelligence through the act of mood changing or cycling. Lastly, mood can facilitate thought by representing implied information about past experiences.

The third Branch, emotional understanding, represents the ability to analyze emotions, understand their probable patterns over time, and recognize their outcomes. The development of this branch corresponds with the development of language and propositional thought (Mayer, Salovey, \& Caruso, 2004). This is the branch that most resembles conventional intelligence (Mayer, 2000). As is conventional intelligence, this third branch involves processing which specific functions include understanding, abstracting, and reasoning about emotional information. This mental processing involves naming feelings, understanding the connections and combinations they reflect, and the transitions that they undergo.

The fourth Branch, emotional regulation, represents emotional management to promote emotional and intellectual growth. Openness to emotions is the initial point of emotional regulation (Mayer, 2001).Openness to emotional information will allow one to understand one's emotional world. When one is open to feelings of anger, he is able to see personal injustices done; or when one is open to sadness, he is able to appreciate personal losses. Openness is not the end of emotional management: An individual who is open to his or her own feelings uses the information from the perception (the first branch), integration (the second branch), and understanding of emotion (the third branch) to best manage his or her emotions.

The hierarchy of the Branches, from perception to management, represents the extent to which the competency is integrated within the individual's personality. This model proposes that Branch 1, perception and expression of emotion, and Branch 2, the capacity of emotion to facilitate thought, are considered to be distinct areas of information processing that are expected to be organized within the emotion system. Branch 3 involves the ability to understand and analyze emotions, including those that are complex and simultaneous; and Branch 4 involves openness to emotions, and the ability to manage emotions reflectively. There is also a developmental progression of emotional competencies within each branch, from the basic to the more advanced (Mayer et al., 2004).

From within this model, emotional intelligence is defined as:

The capacity to reason about emotions, and of emotions to enhance thinking. It includes the abilities to accurately perceive emotions, to access and generate emotions so as to assist thought, to understand emotions and emotional knowledge, and to reflectively regulate emotions so as to promote emotional and intellectual growth (p. 197).

The mental ability model of Mayer and Salovey (2000) conceives of emotional intelligence as similar to other intelligences such as cognitive intelligence to the extent that it meets three empirical requirements. Mayer, Salovey and Caruso EI model (2000) enumerates these criteria: First, mental problems have definite correct and incorrect answers assessed by systematic scoring method; second, it correlates with other measures of mental ability; and third, ability increases with age.

The use of integrated definition of emotional intelligence within the ability model has many scientific advantages:

First, the ability model definition excludes personality attributes, such as initiative, as this is conceptually separable from and is not directly associated to emotional intelligence. The clarity of the EI definition within the ability model allows scholars and practitioners to communicate clearly about the subject matter that is measured or studied, to effectively integrate EI with other variables being studied, to differentiate EI from other personality variables, to use measures with confidence that the measure will assess the EI (Mayer, et al., 2000). The Mayer and Salovey EI model predicts that individuals with high levels of emotional intelligence have probably been raised with emotionally adaptive households; are less likely to act defensively; are able to perceive emotional issues effectively; choose healthy role models for emotional health; are able to express their feelings openly, and have knowledge in specific areas such as social problemsolving, moral or spiritual feelings, and leadership (Mayer \& Salovey, 1995).

Furthermore, this EI model also predicts that individuals with higher levels of emotional intelligence are likely to have better social support and fewer problematic relations; are more satisfied with their social interactions and appear to receive more social support; and they seem to be more successful at evading fights of a social nature, arguments or interpersonal violence. In essence then, high EI involves increased success at resolution of personal conflicts and decreased levels of interpersonal conflict (Mayer, Salovey, \& Caruso, 2004). 
The succeeding part of this review is to show two other models of emotional intelligence: the Bar-on Model of emotional intelligence and the Goleman model of emotional intelligence.

\section{Bar-On model of Emotional-social intelligence.}

Another model of emotional intelligence was proposed by Bar-On (1997) who was among the first to develop assessment measures for emotional intelligence and who used the term "emotional quotient."

Bar-On (1997) describes emotional intelligence as "emotional-social intelligence is a cross-section of interrelated emotional and social competencies, skills and facilitators that determine how well we understand and express ourselves, understand others and relate with them, and cope with daily demands, challenges and pressures" ( $p$. 14 ).

Emotional intelligence is conceived as a range of emotional and social skills that affect intelligent behaviour. In this model, Bar-On (1997) proposed five components of emotional intelligence: (a) intrapersonal, the ability to understand and express one's feelings and self; (b) interpersonal, the ability to be aware of, understand and relate to others; (c) stress management, the ability to deal with demanding situations; (d) adaptability, the ability to adapt to a changing environment; and (e) general mood, which involves self-motivation.

In the Bar-On EI model (2006), within each component are subcomponents of emotional competencies. The intrapersonal component includes self-regard, emotional self-awareness, assertiveness, independence and self-actualization. The interpersonal component involves empathy, social responsibility, and interpersonal relationship. Stress management factor involves stress tolerance and impulse control. Adaptability or change management includes reality testing, flexibility and problem solving. The factor general mood involves happiness and optimism.

The Bar-On EI (2006) model links emotional intelligence to the probability of success rather than to actual performance or actual success. This model predicts that individuals who possess emotional competencies are better able in meeting environmental demands than individuals with poor emotional skills. Bar-On (2006) considers difficulty with coping to environmental demands and pressures as deficiency in the subcomponents of reality testing, problem solving, stress tolerance and impulse control. Overall, the Bar-On EI model considers emotional and cognitive intelligence as essential components to an individual's general intelligence, which in turn gives an indication of his or her potential for success (Bar-On, 2006).

The Bar-On EI model proposed to combine what are generally considered as mental abilities with other qualities distinct from mental ability as personal autonomy, self-esteem, and affect. This attempt to combine mental ability and non-mental ability characteristics makes the Bar-On model a mixed model. In this perspective, EI is conceived as a personality trait or set of traits that relate to emotional management and functioning (Petrides \& Furnham, 2003). Because in this model, EI is not perceived as a cognitive ability in the traditional sense, assessment with a questionnaire is acceptable (Zeidner, Roberts, \& Matthews, 2009).

EI scholars such as Zeidner et al., (2009) consider the Bar-On model as systematic in its approach in its attempt to outline the specific abilities that affect adjustment to real-world environment.

The Bar-On Emotional Quotient Inventory is regarded as one of the first systematic measures of EI. It is shown to have met conventional psychometric criteria, and its scales show acceptable internal validity as well as convergent validity (Bar-On, 2004). This measure has also been shown to correlate significantly with other assessment tools of wellbeing and mental health.

The Bar-On EI model, although extensive, remains conservative in its predictive claims (Mayer et al., 2000). For example, while this model predicts success, Bar-On described success as the outcome of personal striving.

\section{Daniel Goleman theory of personal and social competencies}

This review presents Goleman's EI theory to examine how it contrasts to other EI model. The Goleman emotional intelligence model outlines four key emotional intelligence constructs The first construct is self-awareness which is the ability to accurately perceive one's feelings and includes emotional competencies; the second, self-management, relates to the ability to regulate one's emotions and impulses and the ability to adjust to changing environmental conditions; the third, social awareness involves the ability to understand and respond to another's emotions; and, the fourth construct, relationship management .

Goleman (1995) suggests that emotional competencies are learned and are thus not innate talents and further posits that individuals possess a general emotional intelligence which affects their ability to learn emotional competencies. Goleman (1995, p. xii) describes "the abilities called here emotional intelligence, which include self-control, zeal, and persistence, and the ability to motivate oneself. Further, Goleman asserts, "there is an old fashioned word for the body of skills that emotional intelligence represents: character" (Goleman, 1995, p.28).

Goleman's EI theory has been criticized on many fronts. Critics view Goleman's EI theory as extending the limits of the general intelligence theory (Zeidner, et al., 2009). For example, Goleman (2001) includes qualities that reflect personality components such as optimism, self-control, and moral character as components of intelligence. Additionally, Goleman (1995) suggested that EI is fluid, that is, it can be learned and developed over time. 
This is in contrast to the view of cognitive intelligence as relatively stable. Furthermore, Goleman (1995) argues that EI is related to moral character; whereas, conventionally, intelligence is considered as a set of capabilities and skills that serve the motives of the well- and the ill-intent. Central to the critique of the Goleman EI theory is its inclusion of every positive characteristics, such as sensitivity and optimism, that cannot be considered as cognitive intelligence (Zeidner et al., 2009). Zeidner et al. (2009) also point to the circularity of the EI definition: Goleman (1995) argues that the EI qualities listed in his framework are emotional competencies, and hence, learned based on emotional intelligence. In addition, the Goleman EI definition emphasized that EI is learned and developed over time. This is in contrast to what psychological theories hold which conceives of mental ability as aptitude, that is, there exists a natural disposition to learn certain mental skills (Zeidner et a.l, 2009).

\section{Synthesis}

The Bar-On and the Goleman EI models are generally considered as mixed models (Mayer, Salovey, \& Caruso, 2000) in that both initially conceived of EI as a mental ability and that both expanded the conception of EI by including "non ability traits" (Mayer et al., 2000, p. 402).

The strengths of both of these mixed models of EI are the breadth of the models. Both include a wide range of traits with face validity such as leadership, empathy, and teamwork. Moreover, these traits resonate with practitioners in the human resource arena and those that hold corporate leadership positions. The claim of predictive validity to life outcomes is considered one of the strengths of the mixed models (Salovey, Brackett, \& Mayer, 2004).

One of the limitations of the mixed models is that the traits outlined in the mixed model are accounted for by the fivefactor model (Digman, 1990, as cited in Salovey, Brackett, \& Mayer, 2004) as well as traits in leadership studies. Additionally, the mixed model of Goleman is ambiguous on how the emotional competencies are organized and how they conceptually differ from each other. Other researchers claim that EI in the mixed model does not exist as a construct distinct from other personality traits (Davis, Stankow \& Roberts, 1998).

In contrast, the Mayer and Salovey model (1990, 1997) highlights emotion themselves and their relationship with cognition, whereas the mixed models of Goleman (1995) and BarOn (1997) focus on mental abilities and other qualities. Goleman's (1995) five-dimension model includes intra- and inter-personal qualities and interaction between feeling and thought. Bar-On's (1997) five-dimension model is also divided into intrapersonal traits and emotional states. Mayer and Salovey's (1997) four-branch model focused on emotional-cognitive interactions.

The general concept of EI in the Mayer and Salovey model $(1990,1993)$ had been shown to be consistent over time. This suggests that the formulation of the EI concept remained, which in turn implies that the concept of EI is distinct in relation to other characteristics of an individual and thus, can be reliably examined.

Mayer (2004) also offered the psychoeducational advantages of their EI model, those that relate to testing and teaching another person about emotional intelligence: He argued that their EI model is sufficiently logical, that it is comprehensible to the general population, and that it allows additional understanding of that part of personality not known before.

In addition, Mayer (2004) argued for the expansive advantages of their EI model. These expansive advantages pertain to the ability of the model to allow a person to explore and understand himself or herself in the context of a coherent EI concept with defined sub areas that is the four-branches of the model. The focused definition of EI allows individuals to differentiate and distinguish it as an essential psychological aspect of the person.

This paper then argues that the Mayer and Salovey definition of emotional intelligence lends itself to be model that can explain the adolescent emotional intelligence: that emotional intelligence as an ability to understand and regulate one's emotions is an ability that can be learned and improved; that with age, an individual's level of emotional competency progresses.

\section{EMOTIONAL INTELLIGENCE AND ADOLESCENT MENTAL HEALTH}

The second aim of this review paper to show and examine the existing literature on the relationship between emotional intelligence and mental health: Specifically, the literature on the relationship between emotional intelligence and anxiety; emotional intelligence and depression; emotional intelligence and resilience; and emotional intelligence and self-efficacy.

Literature suggests that among adolescents, emotional intelligence is found to help reduce stress by decreasing conflict, improving relationships and understanding one's own emotions. This kind of emotional health is fundamental to effective learning and education (Serrat, 2009). Understanding the process and elements of learning, which necessarily involves self-efficacy, self-regulation, and ability to communicate and cooperate, in themselves essential aspects of emotional intelligence, are also critical to student success (Zimmerman, Bandura, \& Pons, 1992).

Stressful events, such as starting college life, moving to a new city, separation from friends, or loss of a parent, can prompt the onset of anxiety symptoms among adolescents. Among adolescents, anxiety disorder can be difficult to diagnose as an adolescent's behavior is often attributed to being "just a phase." When not addressed or left untreated, anxiety disorders can persist and interfere severely with an adolescent's life and can lead to missed school days, strained peer relations, low self-esteem, alcohol or substance abuse (Stein \& Hollander, 2001). 
Moreover, anxiety is the most common emotional and mental health problems that occur during adolescence. As many as 1 in 10 adolescents suffer from anxiety disorder, with more females than males affected (Bell, Foster, \& Mash, 2005). This is consistent with the study of Lewinsohn, Lewinsohn, and Allen (1998) which showed prevalence of anxiety disorders among females, and that this prevalence appears early in life, at age six, and that females are shown to be twice as likely to experience anxiety disorder than are males. About half of adolescents with anxiety disorders are co morbid with other mental or behavioral disorders, or with a second anxiety disorder, depression (Aina \& Susman, 2006).

Among adolescents, depression can be a temporary response to stressors (Chua, 2002). A depressed mood is not uncommon due to maturation, the stresses connected with it, the impact of hormonal changes, and independence issues with parents. The study of Dulcan and Wiener (2006) showed that depression, as is anxiety, is difficult to diagnose in adolescence as normal adolescent behavior is marked by fluctuations of moods.

Depression is also manifested differently among adolescents. Prolonged emotional pain may also lead to serious physical problems as in erratic eating and sleeping habits (Foa \& Andrews, 2006). When left unrecognized, unaddressed or untreated, depression and anxiety impact every aspect of an adolescent's life (Saluja, Iachan, Scheidt, Overpeck, Sun, \& Giedd, 2004).

The negative effects of teenage depression go far beyond feelings of melancholy: those who are seriously depressed think of and speak of attempts at suicide (Wolf, 1998).

On the other hand, studies have shown that emotional intelligence has a protective effect against suicidal ideation and attempts (Cha \& Nock, 2009); against stress (Mikolajczak, Menil, \& Luminet, 2007); and against depression (McDougall, 2006). Moreover, studies reveal that emotional intelligence has a facilitative effect on overall health and life satisfaction (Landa, Zafra, Martos, \& AguilarLuzón, 2006).

This part of the review paper presents and evaluates the literature that shows that emotional intelligence predicts mental health of adolescents: Specifically, this paper maintains that emotional intelligence negatively predicts anxiety and depression; and emotional intelligence positively predicts resilience and self-efficacy.

\section{Mental Health}

Mental health may be defined from a deficit model and a positive model. In the context of deficit model, mental health may be described as the absence of or lack of diagnosable disease. On the other hand, from the positive model, mental health is defined as a state of physical, social, and mental well-being (Creek \& Lougher, 2008). The definition from the World Health Organization (2005) corresponds closely to the positive conception of mental health: that it is as a state of "well-being in which the individual realizes his or her abilities, can cope with normal stresses of life, can work productively and fruitfully" (p.18).

The Health Education Authority (1997, as cited in Creek, Lougher, \& Van Bruggen, 2008) described mental health as the form of emotional and spiritual resilience, the ability to withstand taxing demands and daily challenges. The Scottish Public Mental Health Alliance (2002, as cited in Creek and Lougher, 2008) proposed that mental health as a positive resource that enables one to cope with life's demanding conditions and identified sense of self-worth and esteem, empathy, the ability to express emotions, to form and maintain healthy relationships, to effectively communicate as core attributes of an individual with positive mental health.

Mental health is also conceived as a continuum in which individuals vary on a progression of values (Keyes, 2009). This notion of mental health as a continuum conceives of mental health as positive and adaptive functioning on one end, and negative and impaired functioning on the other end (Tsai, 2005). The positive and adaptive end of mental health continuum involves the ability to adapt to change and cope with adversity and to effectively produce positive change. The other end of the continuum involves conditions characterized by changes or abnormalities of mood, thinking or behavior (Alexander, Larosa, \& Alexander, 2009).

Studies have shown evidence for the relationship between emotional intelligence and mental health. The study of Gupta and Shusil (2010) revealed the positive correlation between emotional intelligence and mental health among college students. Other related studies such as that of Velasco, Fernandez, Paez, and Campos (2006) found evidence of the relationship of emotional intelligence to life adjustment of university students. Fernandez-Berrocal, Alcaide, Extremera, and Pizarro (2006) found evidence that the ability to regulate mood among adolescents was positively related to selfesteem; that self-reported emotional intelligence was negatively related to depression and anxiety; and that the ability to discriminate among feelings and the ability to regulate emotional states are linked to better mental health.

Some studies have provided support for the predictive nature of emotional intelligence in adolescent adjustment: For example, Rubin (1999) showed that among adolescents, emotional intelligence was inversely related to aggression; Trinidad and Johnson (2002) revealed that higher emotional intelligence scores were related to lower smoking and alcohol use among high school students. Likewise, Mayer et al. (2001) suggested that emotional intelligence appears to be related to adolescents' ability to organize emotions that affect their peer relationships. Evidence also showed that adolescents with high perception of their emotional abilities, specified as high emotional clarity and repair, generally reported better life adjustment, defined in terms of lower perceived stress and higher life satisfaction (Extremera, Duran, \& Ray, 2006). 
Moreover, Wong and Ang (2007) explored the relationship between emotional competencies (i.e., intrapersonal skills, interpersonal skills, adaptability skills, and stress management) with four factors of maladjustment (i.e., antisocial behavior, anger control problems, emotional distress, and negative self-problems) in an Asian sample. Their results indicate that stress management skills significantly predict overall maladjustment, antisocial behavior, anger control problems, emotional distress and negative self-problems among adolescents. Interpersonal skills significantly predicted negative self-problems whereas intrapersonal skills and adaptability did not significantly predict maladjustment factors. There is, then, growing support that emotional intelligence among adolescents is related to positive behavioral and social outcomes.

The studies mentioned above show that emotional abilities are an important and unique contributor to mental health, but there is still a need for more research aimed at validation of these claims among adolescent samples. To date, there exists a knowledge gap on causal associations of some of EI predictors, EI, and mental health.

\section{Relationship of EI to Resilience and Self-efficacy}

This part of the paper presents the extant literature showing that EI predicts adolescent resilience and self-efficacy. Specifically, this paper argues that certain dimensions of the EI branch, employing emotional knowledge, labeled as flexible thinking, creative thinking, redirected attention and motivation (Mayer \& Salovey, 1990) are linked to resilience and self-efficacy.

In this paper, self-efficacy is conceptualized as a person's beliefs about his capabilities to produce a certain level of performance that exercises influence over events that affect his life (Bandura, 1998); and resilience is conceptualized as the individual's capacity to withstand stressors, to thrive and fulfill one's potential despite of stressors; to see problems as opportunity for learning; to adapt positively and responsibly in the face of adversity, trauma, threat, or stress (Stoltz, 1997).

\section{EMOTIONAL INTELLIGENCE AND RESILIENCE}

Prince-Embury (2007) defined resilience as the "ability to weather adversity or to bounce back from a negative experience" (p. 11). She also identified the three constructs of resilience that allow for a multidimensional understanding and assessment of resilience, namely, sense of mastery, sense of relatedness, and emotional reactivity. This study focused on sense of mastery and emotional reactivity as literature suggests that these two are closely related to emotional intelligence.

Emotional reactivity is viewed as a person's susceptibility or threshold of tolerance to stimulation prior to adverse experiences. The aspects of emotional reactivity include sensitivity, recovery, and impairment (Prince-Embury 2008). Sensitivity is viewed as the threshold of and intensity of emotional response; recovery relates to the ability to return normal functioning after an intense emotional experience; and impairment is the extent to which one is able to maintain emotional balance when emotionally aroused.

Research findings suggest a significant relationship between emotional reactivity, emotional regulation and resilience. For example, Eisenberg, Spinrad, Fabes, Reiser, Cumberland, and Shepard (2004) revealed a significant interaction between the early experience of the child, the development of emotional reactivity, ability for self-regulation, and beginnings of psychological dysfunctions. Thus, emotional reactivity within the average range and that is manageable is an important aspect of resilience (Prince-Embury, 2007).

Mastery affords an individual to directly affect his or her environment, and involves optimism, adaptability, and selfefficacy. Research has also found relationships between EI and optimism (Extremera, Duran, \& Rey, 2007), and EI and adaptability (Landa, Martos, \& Zafra, 2010).

Some studies also point to the relationship between emotional intelligence and resilience. Connor and Slear (2009) examined the association between emotional intelligence, anxiety, and resilience. The results indicated that there exists a positive and significant relationship between emotional intelligence and resilience. From the results, the authors suggested that education must address these particular variables. A similar study by Bumphus (2009) examined the emotional intelligence and resilience of school teachers. Findings reveal that there was a positive relationship between self-reported emotional intelligence and resilience among school principals. Specifically, a school leader's general mood was found to be a significant predictor of resilience.

However, there is clearly a gap in the literature that examines the relationship between emotional intelligence and resilience among adolescent samples, as most studies targeted adult samples. To date, no existing studies have been found that examined the connection of EI predictors, EI and resilience.

\section{EMOTIONAL INTELLIGENCE AND SELF-EFFICACY}

Mayer and Salovey (1990) argued that emotions "subtly but systematically influence some of the component and strategies in problem solving" (p. 196) in four ways: First, emotional transitions may facilitate the production of several alternative plans. Second, positive emotions may change the organization of memory so that cognitive information is better incorporated and differing material are considered as more related. Third, Mayer and Salovey (1990) also suggest that emotion provides "interrupts for complex systems," (p. 196) removing them from a routine level of processing and focusing them on more crucial needs. And last, emotions and moods may be used to encourage and enhance performance at complicated intellectual activities (Mayer \& Salovey, 1990).

Mayer and Salovey proposed (1990) that moods assist in flexible planning, creative thinking, and in the redirection of attention. Moods may facilitate flexibility in planning in that changes in mood assist people in unpleasant moods to break 
their negative emotional set. As a result, they will then be more likely to generate alternate future plans for themselves.

Moods may also assist creative thinking and problem solving through its impact on the organization and information-use in memory. For example, it is easy for people to classify problem features as related or unrelated while they are in a pleasant mood (Isen \& Daubman, 1984, as cited in Mayer \& Salovey, 1990). Creative problem solving may be influenced by the positive impact of clarity in classifying information.

Powerful moods re-direct attention to new problems. When an individual attends to his emotions, it is possible that he is directed away from the present problem, and is led to a new concern of critical importance. In this manner, individuals learn to make the most of the ability of emotional processes to re-direct attention to the most relevant stimulus in their environment. Mayer and Salovey (1990) proposed that "affect can help individuals to reprioritize the internal and external demands on their attention, and allocate attentional resources accordingly" (p. 198).

In sum, Mayer and Salovey (1990) maintained that when individuals approach life tasks with emotional intelligence, they will be able to solve their "problems adaptively" (p. 199) They assert that the kinds of problems people recognize and the way they understand them is, most likely, framed within an internal emotional experience. Placing a problem in an emotional frame, individuals are allowed to be creative and flexible in generating potential alternative solutions to problems and will tend to integrate emotional aspects when choosing from among problem-solutions. This approach leads to behaviours that are "considerate and respectful of the internal experience of themselves and others" (p. 200).

This aspect of emotional intelligence resembles Langer's (1997) concept of mindfulness learning: "the continuous creation of new categories; openness to new information; and an implicit awareness of more than one perspective" (Langer, 1997, as cited in Merriam, 2008). Learning from mindfulness is sourced from different perspectives: seeing problems and solutions from several viewpoints, attributing new meaning to outcomes, with a sense of personal control in the conscious shifting of perspectives, and recognizing the strengths and weaknesses of point of view (Sykes, 2006).

Research findings also point to the predictive relationship between emotional intelligence and self-efficacy. For example, Chan (2004) showed that perceived emotional intelligence is a significant predictor of self-efficacy. Specifically, it was noted that the positive regulation component emerged as the significant predictor for general self-efficacy while empathic sensitivity is found to predict self-efficacy in altruistic behaviors. Other researchers have shown support for the relationship between emotional intelligence and self-efficacy (Penrose, Perry, \& Ball, 2007; Villanueva, Sánchez, \& Howard, 2007; Di Fabio, Giorgi, Majer, \& Palazzeschi, 2005; Huifang, \& Jianping, 2007). Although these studies clearly show a positive relationship between emotional intelligence, its components, and selfefficacy, the sample utilized in these studies were adult samples.

\section{Relationship of EI to Depression and Anxiety}

Mayer and Salovey (2001) posit that at the fourth Branch of EI, individuals are enabled to engage in mood repair strategies. The model predicts that individuals who are incapable of regulating their emotions tend to experience negative affect. The model describes an individual with high emotional intelligence as one who is able to repair his or her negative moods, maintain positive affect.

The model describes the steps in the self-regulatory process. Individuals (a) have confidence in their ability to repair negative moods as they surface, also known as self-efficacy of self-regulation; (b) are able to observe their moods accurately; (c) are able to recognize and distinguish those moods that require regulation; (d) are able to utilize strategies that will moderate negative moods and maintain positive ones; and (e) will evaluate the effective of their mood-regulating strategies. Mayer and Salovey (2001) hypothesized that individuals have different expectancies on the ability to alleviate negative moods: there are those who believe in their capacity to manage their emotions and in their ability to respond actively to stress. There are others who are not confident in their ability for self-mood-regulation. Catanzaro and Greenwood (as cited in Mayer \& Salovey, 2001) found that individuals with low self-efficacy for regulation manifest avoidance responses, depressive, and mild somatic symptoms.

Although the model shows that individuals need to attend to their moods to recognize those that require regulation, the Mayer and Salovey model further suggests that mere "attention to moods may not always be adaptive" (p. 287). Goldman, Nolen-Hoeksema, Morrow, and Frederickson (as cited in Mayer \& Salovey, 2001) found that attention to one's moods relates positively to depression and neuroticism. For example, Swinkles and Guiliano (as cited in Mayer \& Salovey, 2001) found that high mood-monitoring individuals are prone to experience stronger emotional states and greater negative affect. Mood-monitoring, although a neutral activity, may increase rumination and consequently, extend negative affect experience (Nolen-Hoeksema, 1991, as cited in Mayer \& Salovey, 2001).

Mayer and Salovey (2001) suggest that the clarity in discriminating among moods is related to lower social anxiety, depression and physical symptom -reporting as well as to optimism and satisfaction with social and familial relationships. Salovey (2000) found that individuals who discriminate clearly their affective states ruminate less after a negative incident than individuals who report being unclear about their emotions.

Although mood-monitoring is found to promote rumination, mood-labeling enables people to develop adaptive strategies for dealing with their moods. The model suggests that individuals need to first attend to their moods in order to 
distinguish among them. When one is able to recognize and classify his moods, it enables one to prolong or change them. Mayer and Salovey (2000) posit that when attention to moods is not accompanied with discrimination of moods, the process becomes maladaptive that can lead to rumination, which in turn, leads individuals to extremely focus on their mood states without understanding why they are experiencing them. Rumination tends to intensify depression, and consequently, leads to difficulty in dealing with taxing events.

In the model, the ability to reflect upon and manage one's emotions is identified as a major aspect of emotional regulation. The means for emotional self-reflection is through emotional disclosure. In labeling their emotions, individuals are able to set a structure on their experiences. This structure enables individuals to understand and adapt to their experiences, in turn reducing emotional arousal associated with the traumatic experience. The model predicts that the clarity in discriminating among moods is related to lower social anxiety and depression (Mayer \& Salovey, 2001).

\section{EMOTIONAL INTELLIGENCE AND DEPRESSION}

In relation to depression, several studies have demonstrated a relationship between emotional intelligence and depression among university students. For example, the study of Extremera and Fernandez-Berrocal (2006) revealed that high levels of certain EI dimensions such as emotional clarity and mood repair were related to low levels of anxiety and depression, high physical, and social functioning, mental health, vitality, and general health. Furthermore, their study confirmed the predictive value of specific EI dimensions named as attention to emotion, clarity of emotion and mood repair to levels of depression and other areas related to mental, social, and physical health among university students.

A similar research by Downey, Johnston, Hansen, Schemberi, Stough, Tuckwell, and Schweitzer (2008) demonstrated a similar relationship between low emotional intelligence and depression: Their study showed that depressed individuals scored poorly in all emotional intelligence dimensions, which included expressing emotions and being self-aware, understanding the emotions of others, utilizing emotions to guide decision making, managing emotions, and controlling emotions, compared to their non-depressed counterparts.

Specific relationships between severity of depression and the EI dimensions of managing and controlling emotions appeared in the study of Ciarrochi, Deanne, and Anderson (2000). They found that emotional intelligence made a unique contribution to understanding the relationship between stress and three important mental health variables, namely, depression, hopelessness, and suicidal ideation. Their study showed that there is greater suicidal ideation among those low in managing their own and others' emotions. Moreover, Pons' (1997) path analysis result showed emotional intelligence to be positively related to an adaptive form of goal orientation and with life satisfaction and to be negatively related to depression symptomatology. There is, then, evidence from literature that shows a negative relationship between emotional intelligence and depression.

\section{EMOTIONAL INTELLIGENCE AND ANXIETY}

A negative relationship between emotional intelligence and anxiety is implied in much of the emotional intelligence literature. For instance the regression analyses results of Siu's (2009) study reported similar results: the poor use of emotions led to higher levels of problem behaviors, such as depression, aggression and delinquency while a higher degree of selfmanagement led to less anxiety. This study supported the study of Drago (2004) which indicated the relationship of student anxiety to certain emotional intelligence abilities. Using an Asian sample of college students from several universities in Guangzhou, China, Wang (2002) revealed that emotional intelligence scores were negatively correlated with anxiety level and depression. He concluded that emotional intelligence plays an important role in college students' mental health.

Additionally, Summerfeldt, Kloosterman, and Parker (2009) found that emotional intelligence is highly related to social anxiety. The same study also indicated that EI was a dominant predictor of interpersonal adjustment. In particular, the interpersonal and intrapersonal domains of EI contributed significantly to social adjustment. Likewise, Latorre and Montañes (2004) showed a negative relationship between anxiety and emotional clarity, emotion repair, and life satisfaction. The study of Berrocal, Alcaide, Extremera, and Pizarro (2006) showed comparable results where self-reported emotional intelligence was negatively related to anxiety and depression. Jorge and Garcia (2009) examined the interactions between EI and several variables indicative of mental health, personal welfare and life satisfaction among teenagers, and revealed a negative relationship between perceived emotional intelligence and psychological disorders, such as depression and anxiety. The results of these studies support the hypothesis that emotional intelligence is significantly related to anxiety.

In general, aspects of emotional intelligence are inversely related to anxiety and depression and are negative predictors of healthy positive mental health. Although these studies have clearly demonstrated the relationship of anxiety and depression to EI, the relationship of these mental health components and EI to EI predictors are, as of yet, unexamined among Filipino adolescents.

\section{SUMMARY}

This review paper has two-fold aims: Firstly, this paper reviewed the concept of emotional intelligence and related terms such as emotion, intelligence, and emotional intelligence. A distinction was be made between the different models of emotional intelligence, the one that emphasizes mental ability from those that combine mental abilities with personality traits. 
This paper maintains that the Mayer and Salovey definition of emotional intelligence lends itself to be model that can explain the adolescent emotional intelligence: that emotional intelligence as an ability to understand and regulate one's emotions is an ability that can be learned and improved; and that with age, an individual's level of emotional competency progresses.

Secondly, this paper also showed and examined the existing literature on the relationship of emotional intelligence and mental health. Specifically, this paper reviewed the literature on the relationship between emotional intelligence and anxiety; relationship between emotional intelligence and depression; relationship between emotional intelligence and resilience; and relationship between emotional intelligence and self-efficacy. From the examined literature, this paper shows that emotional intelligence negatively predicts anxiety, depression, and emotional reactivity; and positively predicts self-efficacy and resilience, as shown by the existing literature.

\section{REFERENCES}

[1] Ajna, Y., \& Susman, J. (2006). Understanding comorbidity with depression and anxiety disorders. JAOA, 106(5). Retrieved from http://www.jaoa.org

[2] Alexander, L., Larosa, J., \& James, W. (2009). New dimensions in women's health. Canada: Jones and Bartlett Learning.

[3] Bandura, A. (1994). Self-efficacy. In V. S. Ramachaudran (Ed.), Encyclopedia of human behavior (Vol. 4, pp. 71-81). New York: Academic Press.

[4] Bar-On, R. (1997). The emotional quotient inventory (EQ-i): Technical manual. Toronto: Multi-Health Systems.

[5] Bar-On, R. (2006). The Bar-On model of emotional-social intelligence (ESI). Psicothema, 18(Suppl), 13-25. Retrieved from EBSCOhost.

[6] Baron-Cohen, S. (2003). The essential difference: The truth about the male and female brain. New York, NY US: Basic Books. Retrieved from PsycINFO database.

[7] Bell, D., Foster, S., \& Mash, E. (2005). Handbook of behavioral and emotional problems in girls. New York, NY US: Kluwer Academic/Plenum Publishers. doi:10.1007/b107822.

[8] Bumphus, A. (2009). The emotional intelligence and resilience of school leaders: An investigation into leadership behaviors. Dissertation Abstracts International Section A, 69, Retrieved from EBSCOhost.

[9] Cha, C., \& Nock, M. (2009). Emotional intelligence is a protective factor for suicidal behavior. Journal of the American Academy of Child \& Adolescent Psychiatry, 48(4), 422-430. doi:10.1097/CHI.0b013e3181984f44.

[10] Ciarrochi, J. V., Chan, A. C., \& Caputi, P. (2000). A critical evaluation of the emotional intelligence construct. Personality and Individual Differences, 28(3), 539-561. doi:10.1016/S01918869(99)00119-1

[11] Conger, J. (1973). Adolescence and youth: Psychological development in a changing world. Oxford England: Harper \& Row. Retrieved from PsycINFO database.

[12] Connor, B. \& Slear, S. (n.d.). Emotional intelligence and anxiety, emotional intelligence and resiliency. International Journal of Learning, 16(1), 249-260.

[13] Creek, J., \& Lougher, L. (2008). Occupational therapy and mental health. PA: Elsevier Health Sciences. Retrieved from http://books.google.com/books.

[14] Di Fabio, A., \& Palazzeschi, L. (2008). Emotional intelligence and self-efficacy in a sample of Italian high school teachers. Social Behavior and Personality, 36(3), 315-326. doi:10.2224/sbp.2008.36.3.315
[15] Dulcan, M., \& Wiener, J. (2006). Essentials of child and adolescent psychiatry. Arlington, VA US: American Psychiatric Publishing, Inc. Retrieved from PsycINFO database.

[16] Downey, L., Mountstephen, J., Lloyd, J., Hansen, K., \& Stough, C. (2008). Emotional intelligence and scholastic achievement in Australian adolescents. Australian Journal of Psychology, 60(1), 10-17. doi:10.1080/00049530701449505.

[17] Downey, L., Johnston, P., Hansen, K., Birney, J., \& Stough, C. (2010). Investigating the mediating effects of emotional intelligence and coping on problem behaviours in adolescents. Australian Journal of Psychology, 62(1), 20-29. doi:10.1080/00049530903312873.

[18] Drago, J. M. (2005). The relationship between emotional intelligence and academic achievement in nontraditional college students. Dissertation Abstracts International, 65, Retrieved from EBSCOhost.

[19] Fernández-Berrocal, P., Alcaide, R., Extremera, N., \& Pizarro, D. (2006). The Role of Emotional Intelligence in Anxiety and Depression Among Adolescents. Individual Differences Research, 4(1), 16-27. Retrieved from EBSCOhost.

[20] Fernández-Berrocal, P., \& Extremera, N. (2006). Emotional intelligence and emotional reactivity and recovery in laboratory context. Psicothema, 18(Suppl), 72-78. Retrieved from EBSCOhost.

[21] Goleman, D. (1995). Emotional intelligence. New York: Bantam Books.

[22] Goleman, D. (1995). Emotional intelligence: Why it can matter more than IQ. New York: Bantam Books.

[23] Goleman, D. (1997). Emotional intelligence. New York: Bantam Books.

[24] Goleman, D. (1998). Working with emotional intelligence. London: Bloomsburry Publishing.

[25] Gupta, G., \& Kumar, S. (2010). Mental health in relation to emotional intelligence and self efficacy among college students. Journal of the Indian Academy of Applied Psychology, 36(1), 61-67. Retrieved from PsycINFO database.

[26] Huifang, Y., \& Jianping, G. (2007). Research on the emotional intelligence, self-efficacy and achievement motivation of business managers. Psychological Science (China), 30(3), 719-722. Retrieved from PsycINFO database.

[27] Johnson, B. M., Shulman, S., \& Collins, W. (1991). Systemic patterns of parenting as reported by adolescents: Developmental differences and implications for psychosocial outcomes. Journal of Adolescent Research, 6(2), 235-252. doi: $10.1177 / 074355489162006$.

[28] Jorge, M., García, D., \& Mérida, J. (2008). Relaciones entre inteligencia emocional y ajuste psicológico en una muestra de alumnos de enseñanza secundaria. Ansiedad y Estrés, 14(1), 31-41. Retrieved from PsycINFO database.

[29] Keyes, C. (2009). The mental health continuum: From languishing to flourishing in life (2002).Foundations of psychological thought: A history of psychology (pp. 601-617). Thousand Oaks, CA US: Sage Publications, Inc. Retrieved from PsycINFO database.

[30] Landy, F. (2006). The Long, Frustrating, and Fruitless Search for Social Intelligence: A Cautionary Tale. A critique of emotional intelligence: What are the problems and how can they be fixed? (pp. 81-123). Mahwah, NJ US: Lawrence Erlbaum Associates Publishers. Retrieved from PsycINFO database.

[31] Lewinsohn, P., Gotlib, I., Lewinsohn, M., Seeley, J., \& Allen, N. (1998). Gender differences in anxiety disorders and anxiety symptoms in adolescents. Journal of Abnormal Psychology, 107(1), 109-117. doi:10.1037/0021-843X.107.1.109.

[32] Malekar, S., \& Mohanty, R.P. (2009). Factors affecting emotional intelligence: An empirical study for some school students in India. International Journal of Management in Education, 3, pp. 8-28.

[33] Mayer, J. (2004). What Are the Advantages of a More Focused Approach to EI? Retrieved from http://www.unh.edu/emotional_intelligence. 
[34] Mayer, J. D., \& Gaschke, Y. N. (1988). The experience and metaexperience of mood. Journal of Personality and Social Psychology, 55(1), 102-111. doi:10.1037/0022-3514.55.1.102

[35] Mayer, J., \& Geher, G. (1996). Emotional intelligence and the identification of emotion. Intelligence, 22(2), 89-114. doi:10.1016/S0160-2896(96)90011-2.

[36] Mayer, J., \& Salovey, P. (1995). Emotional intelligence and the construction and regulation of feelings. Applied \& Preventive Psychology, 4(3), 197-208. doi:10.1016/S0962-1849(05)80058-7.

[37] Mayer, J., \& Salovey, P. (1995). Emotional intelligence and the construction and regulation of feelings.Applied \& Preventive Psychology, 4(3), 197-208. doi:10.1016/S0962-1849(05)80058-7

[38] Mayer, J. \& Salovey, P. (1997). Emotional development and emotional intelligence. Cambridge University Press: New York.

[39] Mayer, J. D., \& Ciarrochi, J. (2006). Clarifying concepts related to emotional intelligence: A proposed glossary. In J. Ciarrochi, J. Forgas, \& J. D. Mayer (Eds). Emotional intelligence in everyday life (2nd ed). New York: Psychological Press.

[40] Mayer, J., Salovey, P., \& Caruso, D. (2004). Emotional intelligence: Theory, findings, and implications. Psychological Inquiry, 15(3), 197-215. doi:10.1207/s15327965pli1503_02.

[41] Mayer, J., Caruso, D., \& Salovey, P. (1999). Emotional intelligence meets traditional standards for an intelligence. Intelligence, 27(4), 267-298. doi:10.1016/S01602896(99)00016-1.

[42] Mayer, J. D., Perkins, D. M., Caruso, D. R., \& Salovey, P. (2001). Emotional intelligence and giftedness.Roeper Review, 23(3), 131137. doi:10.1080/02783190109554084.

[43] Mayer, J., Salovey, P., \& Caruso, D. (2000). Models of emotional intelligence. In R. Sternberg (Ed.), Handbook of intelligence. Cambridge, UK: Cambridge University Press.

[44] Mayer, J., \& Salovey, P. (1995). Emotional intelligence and the construction and regulation of feelings. Applied \& Preventive Psychology, 4(3), 197-208. doi:10.1016/S0962-1849(05)80058-7

[45] Mayer, J., \& Salovey, P. (1997). What is emotional intelligence? In P. Salovey \& D. J. Sluyter(Eds.), Emotional development and emotional intelligence (pp. 3-31). New York: Basic Books.

[46] Mayer, J., Salovey, P., Caruso, D., \& Sitarenios, G. (2003). Measuring emotional intelligence with MSCEIT V2.0. Emotion, 3, 97-105. DOI: 10.1037/1528-3542.3.1.97

[47] Merriam, s. (2008). Third update on adult learning theory. University Drive, San Marcos, Texas:John Wiley and Sons.

[48] Mikolajczak, M., Petrides, K., \& Hurry, J. (2009, June). Adolescents choosing self-harm as an emotion regulation strategy: The protective role of trait emotional intelligence. British Journal of Clinical Psychology, 48(2), 181-193. Retrieved July 26, 2009, doi: 10.1348/014466S08X386027.

[49] Penrose, A., Perry, C., \& Ball, I. (2007, April). Emotional intelligence and teacher self-efficacy: The contribution of teacher status and length of experience. Issues in Educational Research, 17(1), 107-126 from Education Research Complete database.

[50] Petrides, K. V., Furnham, A., \& Mavroveli, S. (2007). Trait emotional intelligence: Moving forward in the field of EI. In G. Matthews, M. Zeidner, R. D. Roberts, G. Matthews, M. Zeidner, R. D. Roberts (Eds.) ,The science of emotional intelligence: Knowns and unknowns (pp. 151-166). New York, NY US: Oxford University Press. Retrieved from EBSCOhost.

[51] Prince-Embury, S. (2007). Resiliency Scales for children and adolescents: A profile of personal strengths. Minneapolis: NCS Pearson.

[52] Prince-Embury, S. (2010). Psychometric properties of the Resiliency Scales for Children and Adolescents and use for youth with psychiatric disorders. Journal of Psychoeducational Assessment, 28(4), 291-302. doi:10.1177/0734282910366832.

[53] Prince-Embury, S. \& Courville, T. (2008). Comparison of One-, Two-,and Three-Factor Models of Personal Resiliency Using the Resiliency Scales for Children and Adolescents. Canadian

\section{Journal of School Psychology 23,111-25.} doi: $10.1177 / 0829573508316589$

[54] Rubin, K., Bukowski, W., \& Laursen, B. (2009). Handbook of peer interactions, relationships, and groups. New York, NY US: Guilford Press. Retrieved from PsycINFO database.

[55] Salovey, P., Woolery, A., \& Mayer, J. (2002). Emotional intelligence: conceptualization and measurement. In. G.J.O. Fletcher, G. Fletcher, \& M.S. Clark (Eds.), Blackwell handbook in social psychology (pp. 279-307). Oxford, UK.Wiley-Blackwell.

[56] Salovey, P. , \& Mayer, J. D. (1990). Emotional intelligence. Imagination, Cognition, and Personality, 9, 185-211.

[57] Salovey, P., Mayer, J., Goldman, S., Turvey, C., \& Palfai, T. (1995). Emotional attention, clarity, and repair: Exploring emotional intelligence using the Trait Meta-Mood Scale. Emotion, Disclosure, \& Health, 125-154. Washington, DC US: American Psychological Association. doi:10.1037/10182-006.

[58] Saluja, G., Iachan, R., Scheidt, C. Overpeck, M., Sun, W., \& Giedd, W. (2004). Prevalence of and Risk Factors for Depressive Symptoms Among Young Adolescents. Arch Pediatric Adolescent.

[59] Serrat, O. (2009). Understanding and developing emotional intelligence. Knowledge Solutions. Retrieved from http://www.adb.org/documents Medicine. 2004; 158:760-765.

[60] Siu, A. (2009). Trait emotional intelligence and its relationships with problem behavior in Hong Kong adolescents. Personality and Individual Differences, 47(6), 553-557. doi:10.1016/j.paid.2009.05.004.

[61] Steinberg, L., Blatt-Eisengart, I., \& Cauffman, E. (2006). Patterns of Competence and Adjustment Among Adolescents from Authoritative, Authoritarian, Indulgent, and Neglectful Homes: A Replication in a Sample of Serious Juvenile Offenders. Journal of Research on Adolescence, 16(1), 47-58. doi:10.1111/j.15327795.2006.00119.x

[62] Stein, D., \& Hollander, E. (2001). The American psychiatric publishing textbook of anxiety disorders. Arlington, VA: American Psychiatric Publication

[63] Summerfeldt, L., Kloosterman, P., Antony, M., \& Parker, J. (2006). Social anxiety, emotional intelligence, and interpersonal adjustment. Journal of Psychopathology and Behavioral Assessment, 28(1), 57-68. doi:10.1007/s10862-006-4542-1.

[64] Velasco, C., Fernández, I., Páez, D., \& Campos, M. (2006). Perceived emotional intelligence, alexithymia, coping and emotional regulation. Psicothema, 18(Suppl), 89-94. Retrieved from PsycINFO database.

[65] Villanueva, J., Sánchez, J., \& Howard, V. (2007, November). Trait emotional intelligence and leadership self-efficacy: Their relationship with collective efficacy. The Spanish Journal of Psychology, 10(2), 349-357. Retrieved July 27, 2009, from PsycINFO database.

[66] Wang, C. (2002, November). The relationship between emotional intelligence and anxiety, depression, and mood in a sample of college students. Chinese Journal of Clinical Psychology, 10(4), 298-299. Retrieved July 26, 2009, from PsycINFO database.

[67] Wolf, D., \& Mash, E. (2005). Behavioral and emotional disorders in adolescents. New York: Guilford Press.

[68] Wolfradt, U., Hempel, S., \& Miles, J. V. (2003). Perceived parenting styles, depersonalisation, anxiety and coping behavior in adolescents. Personality and Individual Differences, 34(3), 521532. doi:10.1016/S0191-8869(02)00092-2.

[69] Zeidner, M., Matthews, G., Roberts, R., \& MacCann, C. (2003). Development of emotional intelligence: Towards a multi-level investment model. Human Development, 46(2-3), 69-96. doi:10.1159/000068580.

[70] Zimmerman, B., Bandura, A., \& Martinez-Pons, M. (1992). Selfmotivation for academic attainment: The role of self-efficacy beliefs and personal goal setting. American Educational Research Journal, 29(3), 663-676. doi:10.2307/1163261. 